\title{
AC 2012-4985: SUSTAINABLE INTERNATIONAL DEVELOPMENT AS A PROCESS
}

\author{
Ms. Marissa Jablonski, University of Wisconsin, Milwaukee
}

Marissa R. Jablonski is a Ph.D. student of civil/environmental engineering at the University of Wisconsin, Milwaukee (UWM). She serves as Program Coordinator of the National Science Foundation (NSF)funded FORTE (Fostering Opportunities for Tomorrow's Engineers) program at UWM and works to recruit and retain undergraduate minorities and women to UWM's College of Engineering and Applied Sciences. Jablonski is focusing her dissertation on sustainable oxidation of textile wastewater and is working to create small-scale wastewater treatment units for cottage textile industries. She trained at the National Environmental Engineering Research Institute (NEERI) in Nagpur, India where she worked on biodegradation of azo dye intermediates. Jablonski served as Co-chair of UWM's student chapter of Engineers Without Borders for two years since its inception in 2007 and continues to help design and implement water distribution projects in Guatemala. Jablonski was a 2008 recipient of the NSF Graduate Fellowship Honorable Mention, the 2008 Wisconsin Water Association Scholarship, and the 2007, 2008, 2009, 2010, and 2011 UWM Chancellor's Graduate Student Awards. Marissa is a member of ASEE and EWB. She received her B.S. degree in natural resources and Spanish from the University of Wisconsin, Stevens Point, in 2003, her M.S. degree in civil/environmental engineering from UWM in 2009 and will receive her Ph.D. in civil/environmental engineering from UWM in 2013.

\section{Dr. John R. Reisel, University of Wisconsin, Milwaukee}

John R. Reisel is an Associate Professor of mechanical engineering at the University of Wisconsin, Milwaukee (UWM.) He serves as Associate Director of the Center for Alternative Fuels, and Co-director of the Energy Conversion Efficiency Lab. In addition to research into engineering education, his research efforts focus on combustion and energy utilization. Reisel was a 2005 recipient of the UWM Distinguished Undergraduate Teaching Award, the 2000 UWM-College of Engineering and Applied Science Outstanding Teaching Award, and a 1998 recipient of the SAE Ralph R. Teetor Educational Award. Reisel is a member of ASEE, ASME, the Combustion Institute, and SAE. Reisel received his B.M.E. degree from Villanova University in 1989, his M.S. degree in mechanical engineering from Purdue University in 1991, and his Ph.D. in mechanical engineering from Purdue University in 1994.

(C)American Society for Engineering Education, 2012 


\title{
Sustainable International Development Work as a Process
}

\begin{abstract}
It is the experience of a student chapter of Engineers Without Borders at the University of Wisconsin-Milwaukee (EWB@UWM) that sustainable international development work is a process that requires long-range thought. The majority of engineering students who travel to developing countries with groups like EWB do so for a limited time period of an average of two weeks, one to two times during their entire college career. Many assessments of sustainable development projects completed by groups comprised of these types of students are sometimes categorized as being unbeneficial because of their inherent short-term view. Often an engineering professor or professional mentor serves as the cornerstone of the group to prevent this inconsistency. In the case of this student chapter of EWB, mentors are in the form of students who have traveled more than twice and paid particular attention to the needs of the villages in the region.
\end{abstract}

EWB@UWM works on water distribution and sanitation projects in the northwest highlands of Guatemala working closely with the Guatemalan non-profit organization, Agua Para la Salud (APS). Documenting experiences since its inception in 2007, EWB@UWM has found the process of successful development work to include discussions with experienced development workers, listening to the in-country community paying close attention to passive communication, and returning to the same area to complete subsequent projects.

It is clear to veteran travelers who have returned four and five times and communicate directly with villagers and the staff of APS, that the scopes of the yearly projects are steadily broadening. At this point, the group of veterans has been a part of transitioning APS to new leadership and a new method of finding projects that utilizes an association comprised of 50 Guatemalan village leaders, La Asociación, that prioritizes the area's construction needs. Our EWB group has determined that direct interaction with the villagers is critical to success. For example, it was the belief during the first projects in 2007 and 2008 that chlorination is the preferred and best purification method for the village potable water distribution systems. After deliberation with villagers in 2009 and 2010, many cultural truths that prevent the chlorination systems to ever function are now understood. Presently, the group has plans to discuss slow sand filtration with a community in January 2012 with the hopes of small-scale implementation in January 2013 that can grow to large-scale implementation throughout the year. Based on the experiences of one 5year old chapter of Engineers Without Borders, it has been determined that sustainable international development can only be achieved when viewed as a long-term process.

\section{Introduction}

As explained in a recent article published in ASEE's Prism magazine, Low Cost, High Impact: Student teams devise health technologies for \$2-a-day populations, great interest in sustainable engineering for developing countries is being cultivated by student organizations and professional organizations such as Engineers Without Borders (EWB) and Engineers for a Sustainable World. Individual colleges are starting programs such as Rice University's Beyond Traditional Borders, Pennsylvania State University's Humanitarian Engineering and Social 
Entrepreneurship program, and Stanford's graduate level course, Entrepreneurial Design for Extreme Affordability. ${ }^{1}$ It is no surprise with programs such as these growing in popularity that there is coinciding membership growth in groups such as EWB; there is also growing debate questioning the validity of projects that are purported to benefit developing communities. Often the discussion involves doubt that the help being offered is more than funding and questions whether those helping, most often engineering students from developed countries, learn anything more than a week's worth of indigenous culture. ${ }^{2}$ It is the opinion of many that a more useful involvement is qualified by long-term presence requiring a commitment that is most often not possible for university engineering students. There are programs such as the Peace Corps that offer a two-year stay in a single community that intends, in the case of sending an engineer, to create the most optimal case scenario. However, the Peace Corps is set up in a fashion that neither requires using one's expertise nor, in most cases, elucidates a project development process. Volunteers are often left to themselves to complete a project they have elected. In the case of humanitarian engineering, there is an emphasis placed on an engineering group from a developed nation working with nonprofit organization (NPO) located in a developing nation, preferably run by an in-country native.

The relatively new field of humanitarian engineering includes projects in water sanitation and distribution, food nutrition and aid, shelter and settlement, and overall health. ${ }^{3}$ Like all engineering work, humanitarian engineering also requires feedback from the community it is working with. However, public involvement is vital to the success of humanitarian engineering projects because they are often complete in distant and remote communities that have little to no access to goods and services required for maintenance of said projects. This is another reason for the collaborative work with an in-country NPO and local employees of the NPO. Humanitarian engineering projects need to stand-alone and require appropriate technology and call for education about the process and equipment. Equipment must minimize parts that can break or deteriorate in some way because of the community's inaccessibility to replacing those parts. In EWB@UWM's case, we work with a Guatemalan NPO, Agua Para la Salud (APS), which employs three circuit riders. Circuit riders are masons by trade who are native to the area where work is completed with years of experience completing similar projects. They are paid to re-visit completed projects every three months to make sure that the systems are being maintained and continue to function as intended.

All disciplines of engineering may be included in humanitarian engineering as long as the approach involves the following four criteria: 1. the people receiving the help are the ones asking for help; 2. the help needed should cover one of Maslow's five basic needs: air, food, water, shelter, or clothing but may branch into economic or educational development as well; 3 . the community determined need should benefit from engineering; 4 . communication must involve all parties: those in need, the engineers helping, and any other groups involved including non-profit organizations. ${ }^{3}$ There are, of course, practical and theoretical challenges to humanitarian engineering that involve human realities such as selfishness and greed. A group must consider their motivation before committing to a sustainable engineering project and analyze the answers of the following six questions: what is the background of the community looking for help; will anyone suffer or benefit from the project; who is the owner of the project once it is complete, and if something goes awry, who is to be held accountable; are there any consequences of the project, 
and any unintended consequences; how is the community or its people being viewed, (i.e., they should never be perceived as a group needing pity or hand-outs). ${ }^{3}$

It seems as though one of the toughest parts of humanitarian engineering is finding funding. Most engineering projects obtain funding from government and private industry that focus their efforts on local or national engineering feats with broad outlooks hoping to increase productivity and profits. ${ }^{4}$ In the case of most humanitarian engineering projects, benefits will improve the quality of life for small communities throughout the developing world, but will not often reach the home of funders. In rare cases, low-cost sustainable engineering projects may be developed to benefit developing communities with a secondary outcome for developed communities offering an alternative to a higher cost process in place. Often, however, the lower cost option is not implemented in the developed community because it would in fact cut jobs in industry rather than increase them. Engineers are taught to inherently believe in development since they are in the business of creating solutions to problems. ${ }^{5}$ This creation often leads to a continuum of progress that our nation is well consumed by. Problems that consume the developing world are rarely in need of a highly technical solution, but rather some basic and core engineering and some very deep communication and understanding.

EWB@UWM is training engineering students to consider five billion people on earth who earn less than $\$ 10$ per day and cannot afford the same amenities as the other two billion. They are being trained to consider engineering and construction options that are low-cost but can be high impact for developing communities.

It is the experience of this five-year old student chapter of Engineers Without Borders that the success of humanitarian engineering projects lies deeply in their ability to communicate effectively with communities they work with, their continual return to the same areas year after year, and their close work with the local non-profit groups, Agua Para la Salud and La Asociación. It is the goal of this paper to detail design and travel choices this group has made in the past, lessons they have learned describing why past experiences need to be learned from, and future plans to improve the process of the group to ease methodologies to bring potable water to communities throughout developing communities and continue to improve their humanitarian engineering program.

\section{The Past: 2006-2010}

The student chapter of Engineers Without Borders at the University of Wisconsin-Milwaukee (EWB@UWM) was started in late 2006 by a small group of students with the inclination to work on sustainable development engineering projects in developing countries. The original group size was less than ten with approximately five students doing the vast majority of the work; all with equal interest in humanitarian engineering. An initial survey of the members who joined in the first year of the group's inception concluded that members were approximately one-to-three ratio female-to-male and without exception chose involvement in EWB@UWM to help people and give back to their global community; some mentioned a benefit of international travel. The group was started by this small group of students who found appropriate faculty members and university support. It is the experience of many other EWB student chapters that faculty mentors and advisors had started the chapter and set-up the group welcoming incoming students to join. 
Humanitarian engineering is a collaborative process that originates from those interested; the UWM student chapter of EWB was pioneered by UWM students interested in humanitarian engineering. Initiating the group posed a challenge due to the realities that international travel and dangerous construction work pose to students at a university and the resulting liability the university risks. The majority of work done consists of raising funds for travel, and community outreach to advertise the group in hopes of gaining popularity with industry that would in turn offer mentors and funding to the group. Even in its first days the group did its best to predict what would be best for its future. It was believed and often discussed with great confidence that once a successful project was completed, the group would gain respect and have fewer difficulties gaining funds and freedom.

In anticipation that a future project may encompass a long time span and need the commitment of many students, EWB@UWM decided to commit their work to Guatemala as the other student and professional chapters of Milwaukee had also committed to. The first trip was to be a data collection trip focusing on projects in rural villages in the northwester highlands of Guatemala being shown to the group by a Guatemalan non-profit organization called Agua Para la Salud (APS) with its founder, U.S. citizen, Lynn Roberts. During the data collection trip the group visited seven project sites and acquired similar data from each consisting of: water quality of water to be used for home and school consumption, land surveys of proposed water distribution, and community health assessments. Saving data in a central public location made the data attainable for both the student organization and the Guatemala non-profit group. The seven project sites were chosen by APS based on the need of the community and the commitment shown to APS by the community. Considering that most small communities in this particular region of the world have very low income and are in need of basic systems like potable water, there are countless communities asking for help. It is the communities who start to raise money to put toward their projects that are given attention by APS because the money raised to pay for a freshwater spring, for example, is interpreted as a commitment towards the ownership of their much-needed project. The projects included gravity-fed water distribution, car bridges, and potable water from an open water source such as a pond. EWB@UWM allowed the field-tested experience of APS to delegate their first two projects.

Community health assessments were made using a long list of questions mostly supplied by EWB-USA. The questions were asked of the leaders of each village initially visited. Each village votes on a president and committee leaders to run their local government. There are such committees as water, women, and health. All committee leaders are invited to attend the EWB@UWM community health assessment. For the meeting with one of these villages, Quejchip, the project lead was left alone with the group of committee leaders to present the list of questions while the rest of the students visited a new site to complete the other surveys. Because the project lead was fluent in Spanish she was able to communicate with the group of village leaders. Upon getting to the health questions, she had to repeat many of the questions because it seemed as though the health committee leader was insisting that there were no diseases in the village and never a death. The university student could understand rare disease and rare death, but she could not fathom why there was such a solid affirmation of what she had heard come from the leader as he expressed his answers in front of the four other leaders. It was not until the following year when the group returned and connected with the same villagers that enough trust was gained to offer honest answers to the student group. ${ }^{6}$ It is the opinion of the 
translator who has traveled with the group five out of six times, that the recognition of the traveler's faces allowed the villagers to trust the group and answer questions more openly. The villages EWB@UWM works with were particularly brutalized during Guatemala's 36-year civil war. A recent end to a long history of violence in the area is reason enough to emphasize the need for continuity and commitment even among travelers in the groups that choose to complete humanitarian engineering projects abroad. This history also gives reason for EWB groups to work closely with in-country NPOs to secure safety in locations of political unrest.

The design process started upon return to UWM and lasted an entire year. The following year, the group returned to one of the previously visited villages, Quejchip, to build a gravity-fed water distribution system to benefit 340 people. The village receiving help had a system in place for homes located in the lower part of the village. As families grew, children married and constructed homes at higher elevations. It was these new families who needed water at their homes. This project was chosen as EWB@UWM's first project because it seemed, as something no one at the university had done before, like something the group could successfully complete in a year. It was a relatively short conveyance line of approximately one-mile in length with one 10-cubic meter distribution tank and two spring boxes built to capture the natural mountain spring water. The tank, boxes, and conveyance line were designed during the previous year, some during independent study courses, and others in students' free time using computer programs including AutoCAD and textbooks from coursework. Upon arriving for construction one year later there was one specific change to the system that the village leaders insisted upon: that all of the spring boxes be connected so that if any of the springs dry, every house on the line would still receive water. This was a shock to the group considering that they had tried to anticipate all possibilities for the system, but had never considered this design requirement. It was also a refreshing insight into the way that village leaders consider their community members. The people receiving water from the new distribution system were family and friends of the leaders and it made no sense to plan and design a system that did not benefit all people in the community. They made it very clear that there would be no workers digging trenches, carrying sand, cement, or water to the work site unless the appropriate changes were made.

A second realization was made when work began and the student group was not asked to help in construction as they had anticipated. There were trenches dug by the villagers, concrete mixed by villagers, and the concrete tank and box were built by Guatemalan masons hired by APS. Many of the travelers wondered why they had packed work clothes until they were told not to wait to be asked to work, but just to help all those already working. The communication gap between the villagers and the students was more than expected considering that they spoke a Mayan dialect, Ixil. Only a few of the more educated villagers spoke Spanish. This communication gap often leaves people feeling afraid and vulnerable. It takes courage that not all students were expecting to use. Some of the students became quite disenfranchised with the trip due to this communication gap. It is vital when completing humanitarian engineering projects to utilize appropriate language interpreters; in this case, two interpreters were needed: Ixil to Spanish and Spanish to English. Considering this was only EWB@UWM's second time traveling to the area and only two members of the group were returning, EWB@UWM relied heavily on APS and APS staff to relay cultural messages like this one where no one from the village thought it appropriate to ask for help. It has been perceived at times that even a decade of experience in an area is not sufficient to gain understanding of a native. Using the masons of 
APS has become something that EWB@UWM relies on for cultural interpretation as much as they rely on them for Ixil to Spanish translation. With each completed project, EWB@UWM pick-up extensively more nuances that help their humanitarian engineering approach..

Upon preliminary analysis, it seems that communication between APS and EWB@UWM also was lacking. The students designed a four-sided 10-cubic meter distribution tank; however, upon arrival to the work site, students saw that the masons of APS were building a cylindrical one. The engineering students had to reassess discussions they had with APS and the importance of the shape of their design. They had designed the four-sided structure for ease of calculation, but did not have the experience to ask what was best for the community. It was obvious upon arrival that the cylinder was chosen because of the type of supplies available for construction. The wire used to hold the rebar together to solidify the walls of the distribution tank is circular; to retrain the wire to stand straight as a cubic tank would offer a large challenge in comparison to simply building a cylindrical tank. It did not occur to our group to ask these questions or have a discussion with APS about their normal construction habits. Just as it is for engineers in construction management, it is invaluable for EWB students to arrive at a construction site with the intention to draw as-builts and pay particular attention to construction details. With all of the unknowns that international travel and working in developing communities bring, humanitarian engineering requires paying attention to the many details encompass a project with a special interest in asking questions and starting conversations about any unknowns.

The hydraulics of the first design were analyzed using an advanced excel spreadsheet offered to the group by APS. The design limits were inputted into the spreadsheet and the equations calculated that the water would arrive at the distribution tank. The appropriate technology for land surveying the mountainous and forest terrain of the Guatemalan northwestern highlands, is using an abney level and measuring tape. The group gave special effort to converting survey data from the abney level data. It was not until the students took a hydraulics class that they were able to dissect the spreadsheet and find particular details creating its accuracy.

Quejchip was the first village for whom EWB@UWM designed and built a potable water distribution system. The government had approached APS years ago to explain their willingness and capacity to assist in water projects in the Mayan villages in the Quiche region.

EWB@UWM was informed by APS that the Guatemalan government requires that all new water distribution systems be disinfected by chlorine. The Guatemalan government supplies the chlorine to be used in the chlorination systems. Bacteria are found in the natural mountain springs in the Quiche region of Guatemala most likely because of the porous limestone geography. The damp climate of the region creates sinkholes in the limestone that swallow the land including small animals and feces that may be present. It is the assumption of the APS staff that the sinkholes link with the aquifers that feed the springs that create the drinking water systems being installed, although further investigation is recommended to verify this idea. EWB@UWM installs the Norweco pool chlorination systems that utilize trickle chlorination. The system is shocked and calibrated upon construction. During the second phase of the Quejchip project in 2010 adding more home distribution lines to the complete system, a woman residing in the closest house to the chlorination tank complained of stomach aches condemning the chlorine in the water. It was after much deliberation between the woman, APS staff, and EWB@UWM, that the group determined that the stomachache had occurred days before from 
ingesting untreated water. It is the belief of the student chapter of EWB that chlorine may not be as accepted as necessary to make the use of the disinfection system truly successful. Diego, the head mason of APS, acting as Ixil-Spanish translator confidently assures the group that chlorination is gaining acceptance throughout the region as his work as a regional circuit rider brings him to over 50 villages offering water conservation and disinfection education. His follow-up work with Quejchip acts as an enormous ally to EWB@UWM ensuring long-term sustainability of our project through village education, system maintenance, and communication.

\section{The Present: 2011-2012}

Since its inception there have been many discussions debating the priorities of the group, all ending unanimously that the priority be to work with the villages to benefit their needs. Deep communication is practiced with a focus on listening to the villagers about their project needs. Our practices are based on lessons learned from previous years. For this reason, we emphasize the need for travelers to continue participation with the group and we commit to continue work with APS. It is normal practice that all travel groups, ranging in size from eight to twelve, consist of at least four previous travelers and all travelers must have many hours of volunteer time with the student organization whether that be fundraising, design, or community outreach.

It came to the group's attention during the 2009 trip that the founder of APS was looking for a replacement to fill his position in the next five years. The head mason and circuit rider of APS, Diego Ramirez, was eager to show Lynn his interest and prove his leadership abilities. Our group was the first to volunteer to have Diego manage our next project building the distribution tanks, spring boxes, and nine-mile conveyance line for a two-part two-village gravity-fed water distribution project. The leaders of EWB@UWM believe that an important aspect to the sustainability of humanitarian engineering projects is being run and controlled by locals. In that capacity, EWB@UWM gives ownership of completed projects to the villages for which they are designed and intended. The local NPO, APS, however, is still run by Lynn Roberts, a US citizen. It is the long-term hope of EWB@UWM to elucidate the transition of APS from Lynn to Diego. This particular project was to span two years due to the breadth of the nine-mile conveyance line. Having Diego manage this project gave the group a two-year timeline to work with Diego to successfully build a complete gravity fed potable water distribution system as compared to the one-year it takes to build a much smaller system. During the first year that EWB@UWM worked with Diego, it was obvious that he was very qualified as a project manager but that the cultural nuances present when working with a group from the United States required some attention. It is EWB@UWM's expectation to continue this transition for many years with our end goal in site. This is yet another example of the processes that encompass humanitarian engineering.

Diego shares a sincere dedication to the Quiche region of Guatemala and he can see that it is his job that will bring health to the Mayan people. It is this resolve that allows him to strive to learn the areas of his work that are difficult to learn. For instance, Diego must practice English if he is to work with groups from the United States; he must also practice using computers if he is to assist in the design and double check the work of engineering students. For these things, he is actively taking classes and studies very hard to excel at his practice. The EWB@UWM group shares loyalty to this region of Guatemala and have pledged to continue working with APS. It is 
only through time that EWB@UWM will gain the reputation and trust of the people they are trying to help and also understand as students how their help encompasses more than simply raising the funds for an engineering project. It is the relationships formed with local groups that sustain the trust on which these humanitarian engineering projects are built. Diego's patience and passion for his masonry work have always been apparent, but shown especially when he started discussing with the translators of the group that he was going above and beyond the work of APS by forming a cooperative association with fifty villages in the Quiche region of Guatemala prioritizing the engineering needs of the area. This association will allow EWB@UWM to continue their humanitarian engineering efforts in this area for years to come, open opportunities to other groups who are interested, and clearly communicate to the villages in need the order at which projects will be completed. This peaceful and agreeable discussion between in-country projects was a previously missing link to our humanitarian engineering network.

\section{The Future: 2013 and beyond}

Once the group had taken the task of working with Diego and APS for the combined two-village nine-mile gravity-fed water distribution system, changes became apparent in the monthly Skype conversations about the design of the project, allocation of funds, and the timeline. Diego made himself available to answer questions about all of these things and the project was well on its way. One miscommunication that needs to be addressed is the opinion of chlorination in villages throughout the area. It is the group's understanding that chlorine is not thought of highly but is by law required to be installed to disinfect the drinking water. It is the goal of the EWB group to offer slow sand filtration as an option at individual homes in the area. It is the hope that the interest cultivated in 2011 for slow sand filtration can be drawn upon to build approximately one slow sand filters in Vijolom III in 2012 only to be raised to 10 in 2013 and 100 in 2014. It is clear through EWB@UWM's past experiences that the future humanitarian goals will only be attained through the involved assistance of APS and their native staff.

\section{Conclusion}

It is clear to the EWB@UWM veterans who have traveled more than twice that the work completed by the group should be considered one large project made of individual small projects since each completely builds on the others despite the fact that they are for different villages. For this reason alone, the group considers their sustainable humanitarian engineering work as a long-term process that was started at the end of 2006 and will continue indefinitely as long as there is interest with the engineering students of UWM and those students are able to procure the minimal funding required to construct the designs. Each year's work focuses more communication and logistics, transitioning to a more complete understanding between all groups involved. The design is roughly similar since during the last five years, the group has consistently worked on gravity-fed potable water distribution systems than it does on design. Overall the following outlines the process that this particular student chapter of EWB has followed to procure, design, plan, and construct projects:

1. commit to sustainable engineering work in developing communities;

2. create a relationship with an in-country non-profit organization(s) committed to collaborative work that is willing to follow-up and find projects; 
3. work with the non-profit organization(s) to find communities with needs within Maslow's hierarchy who also show a commitment to finding sustainable solutions to their needs;

4. continue to work in the same geographic area growing trust and relationships for an unregulated extended period of time with a minimum trip frequency of one year;

5. include students and mentors who have traveled in design and logistics teams for new student to look to for advice on which to grow and improve;

6. bring at least one language interpreter/translator abroad with the construction/data acquisition team

7. send returning students and mentors, comprising of up to half of the travel team, abroad in order to gain cohesiveness between projects;

8. listen to cultural needs and norms in order to find alternative solutions without encroaching on them;

9. use appropriate technology;

10. have patience and trust that a return trip may accomplish the task more effectively than forcing a technology immediately.

The process described here inherently offers developing communities allies to improve their living situation and obtain their basic needs. The process also enriches engineering students throughout developed nations with invaluable experience completing tasks outside of their comfort zone. All parties involved develop collaborative relationships that open doors and alter the future of engineering.

\section{References}

1. Grose, Thomas K. "Low Cost, High Impact: Student teams devise health technologies for \$2-a-day populations", Prism, ASEE, October 2011.

2. Riley, Donna. Engineering and Social Justice, Morgan \& Claypool, 2008.

3. Mitcham, Carl and David Munoz. Humanitarian Engineering, Morgan \& Claypool, 2010.

4. Papadopoulos, Christopher, and Andrew T. Hable. "Engineering as an Enterprise of War and Peace", in Engineering in Context, Academica, 2009.

5. Lucena, Juan, Jen Schneider, and Jon A. Leydens. Engineering and Sustainable Community Development, Morgan \& Claypool, 2010.

6. Jablonski, Marissa, Christopher Papadopoulos, and John R. Reisel. "Building Trust During International Development Work: A Case Study of a Recent EWB Project", Proceedings of the American Society for Engineering Education Conference \& Exposition, 2009. 